\title{
Pavement wear process and abrasive wear resistance of asphalt concrete
}

\author{
Rustem Gayfutdinov ${ }^{1}$, Gadel Bajmukhametov ${ }^{1}$, and Eduard Hafizov²* \\ ${ }^{1} \mathrm{SPI}$ «Glavtatdortrans», 420000, Dostoevskij st, Kazan, Russia \\ ${ }^{2}$ Kazan State University of Architecture and Engineering, 420043, Zelenaya st., Kazan, Russia
}

\begin{abstract}
The aim of the article is an improvement of abrasion resistance of materials of road pavements and giving practical recommendations during the pavement designing to the construction organizations. The Prall Test method was used to identify the factors influencing the wear resistance of asphalt concrete. Studied mixtures and materials are typical for the highway construction in the Russian Federation and the Republic of Tatarstan. The influence of such factors as the type of mix, the size of the aggregate, the type of binder and the quality of the aggregate was studied. The study shows that the increase of the wear resistance and coarseness of the aggregate when using a polymer-modified binder and the reduction of the content of air voids increase the wear resistance of asphalt concrete mixtures.
\end{abstract}

Keywords abrasion wear, Prall Test, rutting, abrasion resistance, pavement, studded tire.

\section{Introduction}

Nowadays road construction field in the Russian Federation is under changes. Traditional GOST system loses its relevance due to high pavement loads influence and increasing of materials quality requirements. 6 types of dense-graded hot mixes for the surface course were conventionally used in the Russian Federation since the middle of last century. These are dense-graded mixes of types «A», «Б», «B», «Г», «Д» and high-density HMA according to GOST 9128-2013 «Asphaltic concrete and polymer asphaltic concrete mixtures, asphaltic concrete and polymer asphaltic concrete for roads and aerodromes. Specifications». The HMA type «A» and «B» were the most commonly used mixes (Fig. 1) $[1]$.

\footnotetext{
*Corresponding author: hafizov@kgasu.ru
} 


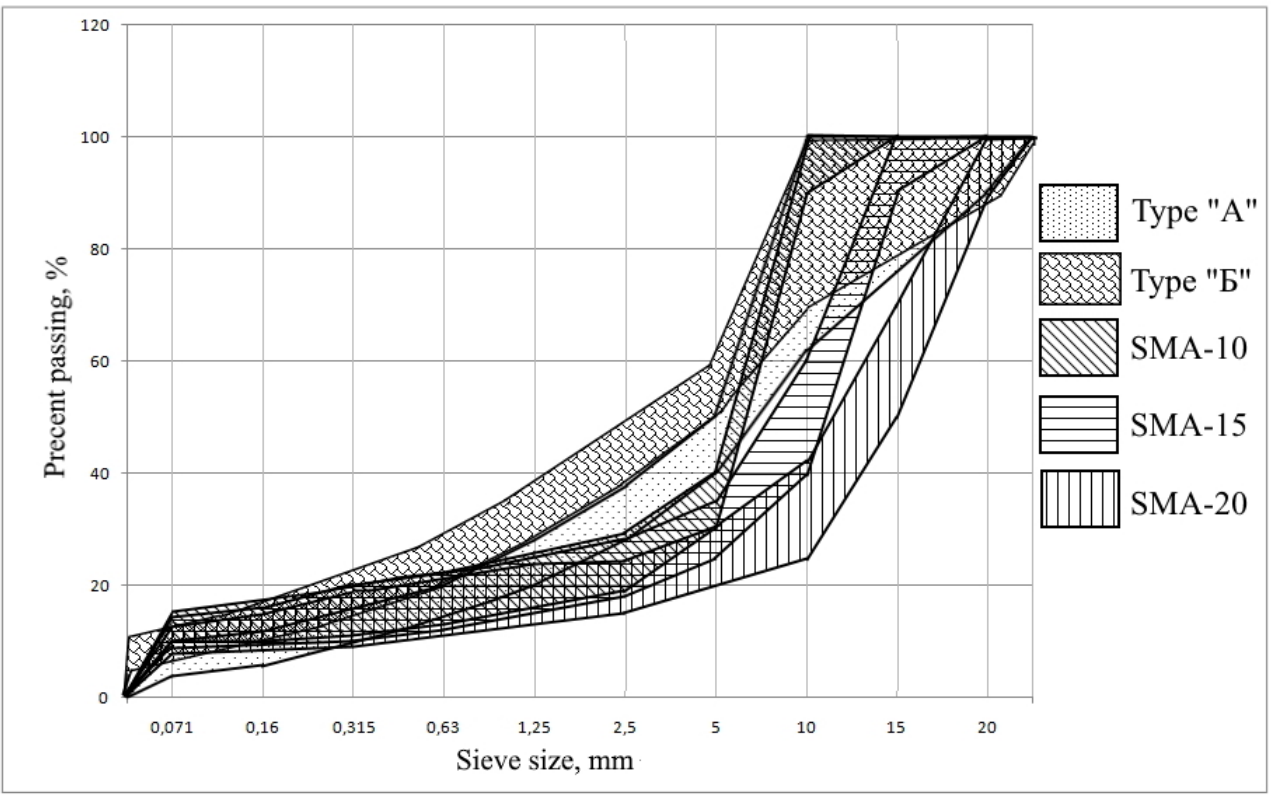

Fig. 1. Mixes grading limits according to GOST 9128-2013 and GOST 31015-2002.

SMA mixes began to be used at the beginning of XXI century. In the beginning, it was regulated by GOST 31015-2002 «Bituminous stone mastic mixtures and stone mastic asphalt. Specifications» and this GOST was harmonized with outdated GOST 9128-2013. Requirement properties and testing methods were not considered to the Europe and USA standards and methods. The opening shapes of testing sieves were round despite to the square opening shapes of the most commonly used imported asphalt plant vibrating screens. The SMA 10, SMA 15 and SMA 20 mixes were the most commonly used for the surface courses (Fig. 1).

The requirements for the Russian road network have changed since the end of XX century. The traditional Russian mix design system was incapable to forecast and prevent such defects of the road pavement as a wear ruts [2], and hardly effective for the preventing the road pavement deformation due to increased loadings. SPI «Glavtatdortrans» with KSUAE began to study origin of this road pavement defect after the rut propagation on the street network of Kazan. Researchers made a conclusion, what the abrasion wear was the main reason of the rut propagation of the road network in the cities of Republic of Tatarstan (Fig. 2).
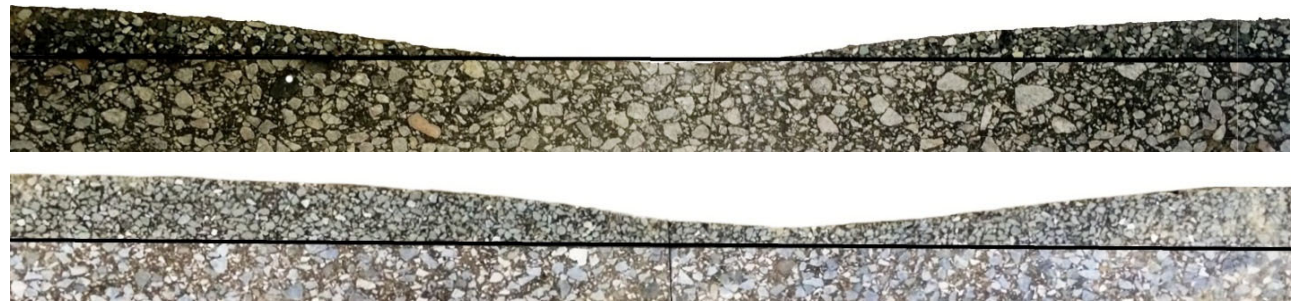

Fig. 2. Abrasive wear of the road surface in the Kazan.

SPI «Glavtatdortrans» made aggregate choosing requirements as a preventive measure for the road construction organization of the Republic of Tatarstan. The high abrasion resistance aggregate with Nordic Abrasion Value less than $10.4 \%$ that corresponds to the 
AN10 grade by EN 1097-9 «Tests for mechanical and physical properties of aggregates Part 9: Determination of the resistance to wear by abrasion from studded tires - Nordic test» has to be chosen for the high traffic streets of the main cities of the Republic of Tatarstan (Nizhnekamsk, Almetyevsck, Naberezhnye Chelny, Kazan). Nordic Test is an European testing method of coarse aggregate that shows a good correlation to the road abrasion wear under a studded tires loading. It is widely used in Northern Europe where studded tires are often used in the slippery winter conditions. Since 2015 this method is used in the St. Petersburg during designing the main streets of the city. The using of this method was regulated by «Regulations on the requirements for the selection of compositions of all types of hot asphalt concrete mixtures used in the construction and repair of asphalt concrete pavements in St. Petersburg».

In 2019, new standards were introduced for superpave mixes (asphalt pavement with superior performance) and the Marshall mix design system. This led to the harmonization of the design of the mixes of Russia and Europe. Traditional Russian sieve opening shapes and sizes are refused in new series of standards, that allows to use the European testing and plant equipment without any limits. Besides it, the main advance of the well-studied effective mix designing systems is a possibility to predict and prevent the most of the present road pavement defects. Particularly, Marshall mix designing systems allow to use the abrasion-testing methods as a Prall Test.

Today SPI «Glavtatdortans» as a contracting authority in the Republic of Tatarstan has a well-equipped testing laboratory to ensure high quality road construction, including Prall Test equipment for predicting wear rut. SPI «Glavtatdortrans» cooperates with regional contractors to improve the quality of road network and helps to design durable pavements.

Pavement wear problem was studied in the several studies. This is a common problem in countries where studded tires are used in winter slip conditions. For instance, in the United States abrasion wear is an acute problem in the northern states. For example, a study by the Oregon Department of Transportation analyzed data from 1995 to 2014 [3]. The analysis was based on annual coverage data for the study period and data from Portland State University. At the same time, due to the irreversibility of this road defect, road maintenance costs the United States is high. Based on an estimate by the Washington Department of Transportation, the annual cost of eliminating the effects of wear rutting is between $\$ 7.8-11.3$ million. According to reports, damage from studded tires in Oregon is about $\$ 7$ million annually. In Alaska, the same figure is $\$ 5$ million.

According to studies in Sweden, the damage from studded tires in winter is more than 450,000 tons of material per year, at a cost of $\$ 35$ million. In addition to the costs associated with the direct repair of the roadway, there are costs associated with cleaning the roadside area and road signs from dust. Studies by Oberg estimate these additional costs at \$ 4-8 million. These and many reasons led to a natural decrease and legislative regulation of the use of anti-skid studs [4].

Abrasive wear of the coating leads to the spread of the dust in the roadside area. At the same time, this dust is finely dispersed and is capable of causing damage to humans and the environment. Many studies of the composition of the contaminants have been carried out and the particle size and distribution have been identified, as well as the harm to human health in the roadside area has been highlighted [5].

Most authors [6] came to conclusion that abrasive wear of the pavement primarily depends on the several factors as a:

- mix grading;

- aggregate size;

- aggregate type;

- binder properties. 
Kekec et al. [7] studied the aggregate wear and came to the conclusion that the most wear-resistant rocks are rocks with high hardness, such as volcanic rocks. For example, Sweden and Finland decided to use porphyry to reduce abrasive wear of the coating, which are widespread in northern Europe. In a study conducted in the United States, it was proposed to use metallurgical slags for these purposes [8]. The aggregate size can be increased to increase wear, but this will increase the driving noise [9].

This study describes the test methods for the abrasion resistance of road materials determination and also presents specifications of the most important results of the study. As a result of the study, it has been possible to survey a number of influential factors connected with asphalt concrete grading and using materials, e.g. importance of aggregate quality, aggregate content, aggregate size, type of binder and degree of voids content. The aim of this study is a determination of influence of these factors to make possible an improvement of the asphalt concrete abrasion resistance. Materials and asphalt concrete mixtures used abroad and in the Russian Federation are different, therefore the value of this study lies in the study of materials used by road organizations of the Republic of Tatarstan. 25 different mixes with different materials and parameters were selected and investigated to identify these factors and their assessment.

\section{Materials and methods}

25 different samples were tested. Samples were taken from the mixes, which the road construction organizations of the Republic of Tatarstan used in the construction of asphalt roads. The asphalt mixes grading - according to the Fig. 1. The difference of nominal sizes of aggregate with Europe and US is that the sieve's opening shape in Russian standards is round [10].

The Prall test was used for the abrasion testing of the pavement material. The Prall Test was developed by the VTI in Northern Europe. It described in EN 12697-16 «Bituminous mixtures - Test methods for hot mix asphalt - Part 16: Abrasion by studded tires» in Europe and in GOST 58406.5 «Automobile roads of general use. Asphalt concrete mixes for road and asphalt concrete. Method for determining abrasion» in the Russian Federation. The Russian test method corresponds to European. The Prall test shows a good correlation between studded tire abrasion on road and laboratory testing [4, 11]. This testing method is performed by subjecting an asphalt specimen to an abrasive loading by hitting the specimen by steel balls under the cooled water. The abrasion wear value $\left(\mathrm{cm}^{3}\right)$ is used to determine the Prall test abrasion value.

The Nordic test was used for the coarse aggregate wear resistance testing. This test is also known as a ball mill test. Today the European standard EN 1097-9 is used when carrying out this test in the Russian Federation. The Nordic test is recommended for use in such regions as Tatarstan, Leningrad region etc. As an example, we can cite the «Regulations on the requirements for the selection of compositions of all types of hot asphalt concrete mixtures used in the construction and repair of asphalt concrete pavements in St. Petersburg. 2015». Abrasive wear of the aggregate includes rotating of the sample with water and $7000 \mathrm{~g}$ of steels balls in the drum with three shells. The abrasion value in this method is defined as a lost mass of the sample (\%) after 5400 rotation with speed of 90 rotation per minute.

The value of saturation test method according to a GOST 12801-98 «Materials on the basis of organic binders for road and airfield construction. Test methods» was used for the percentage of air voids determination. The trivial method using the bulk and maximum specific gravity is more accurate than the saturation test method. However, the value of saturated water depends on a percentage of air voids [12] and this method is fast and acceptable for the case when the evaluation of maximum specific gravity is impossible. 
This method was commonly used for the mixes according to the traditional GOST system and is easy to perform.

\section{Results}

25 samples were selected to assess the influence of the main parameters of the mixture on its wear resistance. An assessment was made of such parameters as: air voids content, type of binder, abrasion resistance of aggregate and mix grading.

Three groups of samples were tested for the determination of the effect of air voids. The degree of saturation of the sampled mixes were determined for the evaluation of air voids. The result of the testing is shown below.

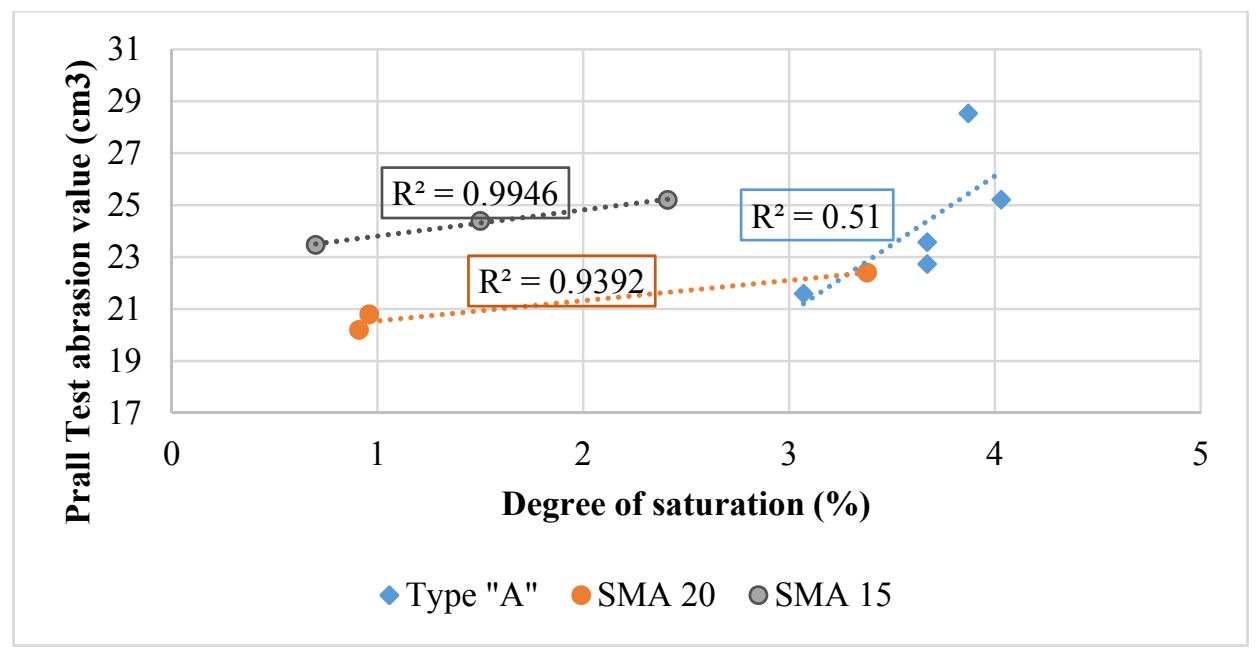

Fig. 2. Dependence of Prall Test abrasion value on air voids content of the samples.

Two groups of samples were chosen for the assessment of the type of binder influence. One of them with common binder and second with styrene-butadiene-styrene polymer modified bitumen. The result of the testing is shown below.

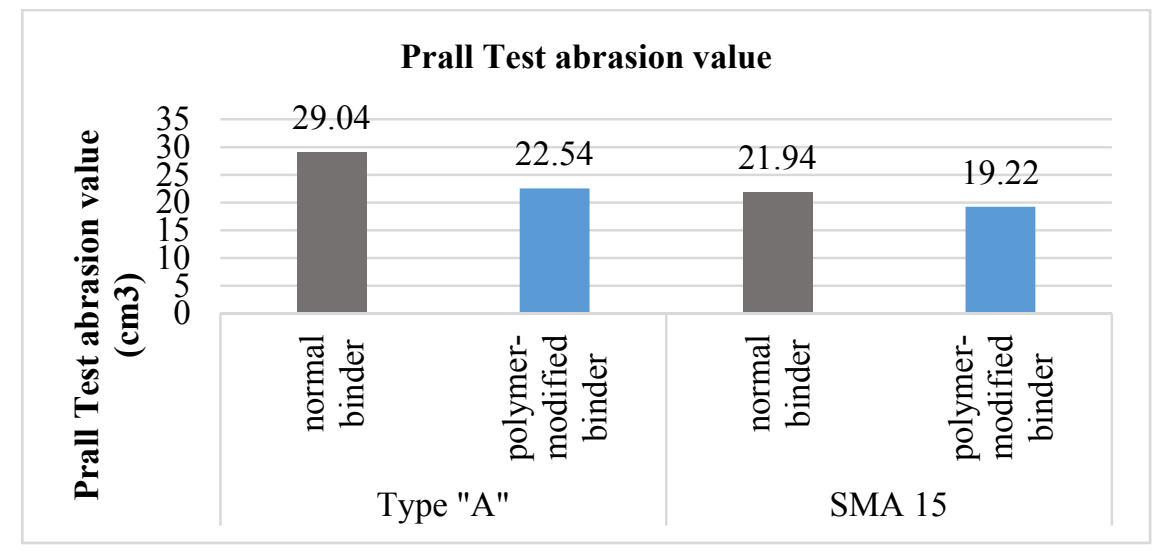

Fig. 3. Dependence of Prall Test abrasion value on type of binder. 
Three groups of the samples with different types of aggregate were chosen for the determination of the aggregate abrasion resistance influence. The ball mill value of each aggregate type was evaluated. The result of the test is shown below.

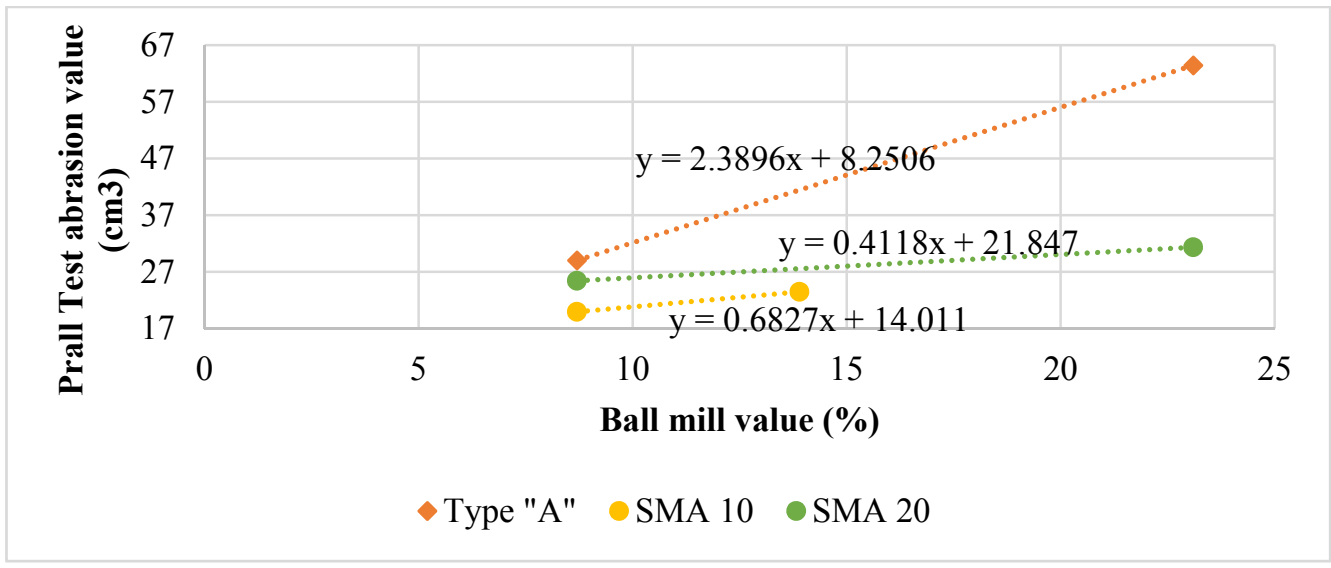

Fig. 4. Influence of the aggregate abrasion resistance on the asphalt concrete abrasion resistance

Two groups of different mixes were chosen to evaluate the mix grading influence. Each group of the samples consists of one type of aggregate and binder. Type «A», SMA 10, SMA 15, SMA 20 mixes were tested. The result is shown below.

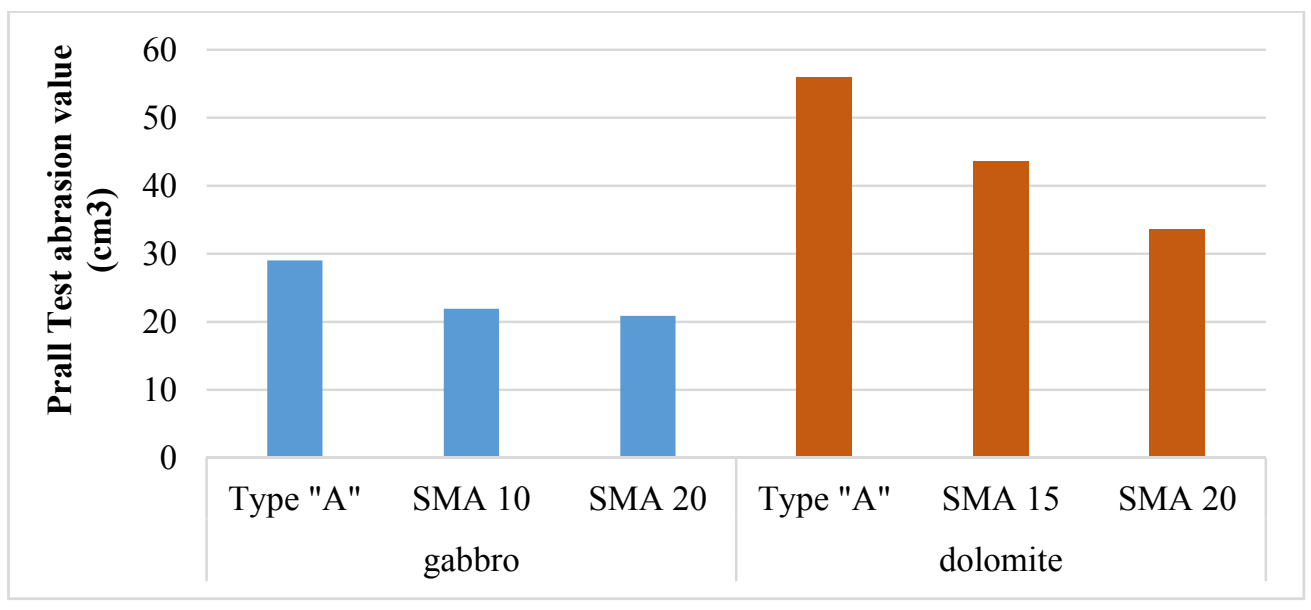

Fig. 5. Influence of the mix grading on the asphalt concrete abrasion resistance.

\section{Discussion}

Test results shows a vital role of the each tested parameters on the abrasion resistance of asphalt concrete. It is worth nothing that only a qualitative assessment was made; for a quantitative assessment, a much wider series of experiments is needed.

It was concluded based on testing of three groups of samples that the content of air voids affects the abrasive wear. Air voids content (Fig. 2) reduces an abrasion resistance of the asphalt concrete; there is a clear correlation between the content of air voids and wear. It can be explained by the loosing of asphalt particles due to lack of adhesion around the pores. Particle loose process can be also explained by the simple mechanical model [13], 
there abrasion wear includes three simple process, that can be explained as an aggregate plugging, aggregate loosing and aggregate cracking (Fig. 6). Air voids also influence the aggregate cracking that can occur due to compaction damage during the road construction. Air void content also can influence the other properties of asphalt concrete as a tensile strength resistance, freeze resistance and fatigue life [14]. However, less air voids can lead to high rutting just as a low compaction can [15]. Difference in the air void content in these experiments can be explained because of low compaction or mix grading difference [16]. But there is no difference between the characters of air voids, because samples are subjected only to an abrasion loading, excluding high strength loading.

a)

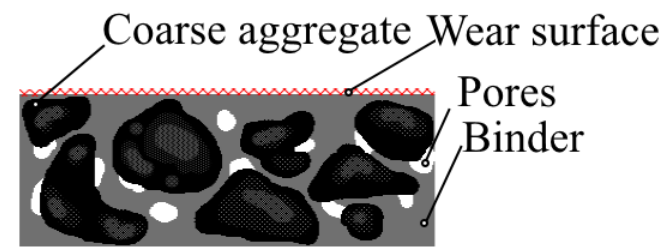

b)
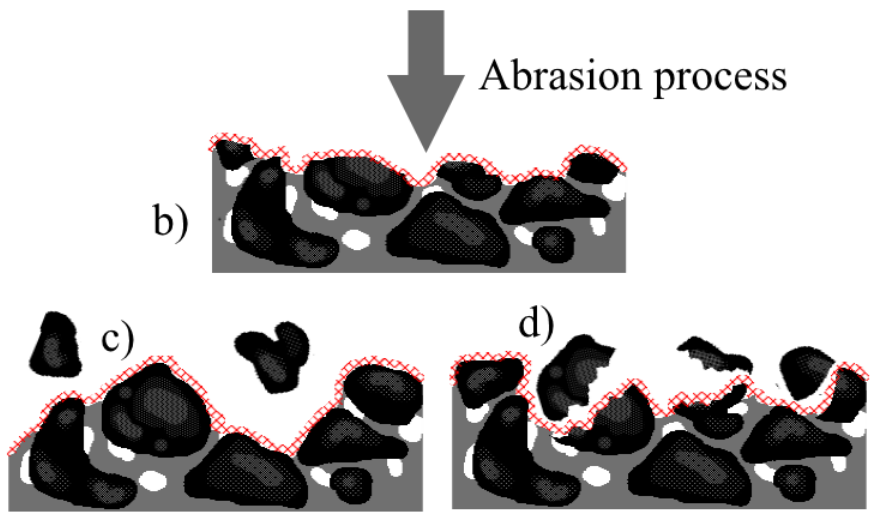

Fig. 6. Asphalt concrete abrasion wear process: (a) Origin asphalt concrete before abrasion, (b) regular abrasion process is plowing, (c) particle removing, (d) cracking.

There is a clear correlation between the type of binder and abrasive wear of asphalt concrete (Fig. 3). Simple abrasion wear model (Fig. 6) can also explain the binder type influence. Therefore, the good elastic properties of the styrene-butadiene-styrene polymer modified bitumen reduce the particle removing and cracking (Figs. 6, c, d) processes. Experiment shows an improving of the asphalt concrete abrasion resistance for 10-22 percent. Effect of binder type on the dense graded mix is more than on the SMA, this fact can be explained by the large role of the particle removing in the case of dense graded mixes abrasion wear. But we can confidently talk about the advisability of using a polymer modified binder in both cases. Styrene-butadiene-styrene polymer modified bitumen is vital component of high-qualified asphalt concrete that improves the mechanical and physical properties of the pavement [17].

Experiments to assess the impact of aggregate quality have confirmed the findings of other scientists $[7,18,19]$. The wear rate of aggregate is less than the wear rate of binder and pores in the case of asphalt concrete. Therefore, wear resistance of asphalt concrete primarily depends on the wear resistance of asphalt aggregate, which is perfectly observed in practice $[5,6]$. An increase in the quality of the aggregate and a decrease in the ball mill value by 5 percent in our case (Fig. 4) reduce the wear of the mix by $10 \%$.A decrease in the ball mill value by 15 percent reduces the wear of the mixture by more than $50 \%$ in the case of the type «A» mix grading. Accordingly, ensuring adequate resistance to contact damage 
is critical to ensuring proper coating characteristics in terms of surface wear [20]. Experimental relationships were obtained between the wear of asphalt concrete and the wear resistance of the aggregate based on the data obtained. They are shown in the Fig.4. At the same time, additional research is needed to refine them numerically. But despite this, it is possible to accurately judge the nature of the dependence and the effect of the quality of the aggregate on the wear resistance of asphalt concrete.

The effect of mixture type on wear has confirmed the findings of other researchers. It is widely known that SMA mixes are more wear-resistant than dense-grading mixes. It is well known that the maximum aggregate size has a great influence on the wear resistance of asphalt concrete. Obviously, in the case when the aggregate will provide the main resistance to the wear resistance of asphalt concrete, it is the coarsening of the grain composition that will increase the wear resistance. In addition to an increase in the roughness and wear surface area [21,22], a decrease in the size of the aggregate increases the chances of it flying out and chipping out of the matrix. However, unlimited coursing of the aggregate is unreal due to the increase in environmental noise [9, 23]. So it was obtained in our experiment that the most abrasive resistant mixes is a SMA 20 in the both cases of dolomite and gabbro aggregate. SMA 10 and SMA 15 are less resistant mixes due to less size of aggregate. Dense-graded asphalt concrete underwent the greatest wear during the tests; it is about 1.5 times more than SMA 20 abrasive wear during the test in the both cases of dolomite and gabbro aggregate. Thus, the choice of the type of asphalt concrete mixture in the direction of SMA with a large aggregate of $20 \mathrm{~mm}$ in size makes it possible to increase the standard service life of asphalt concrete by one and a half times minimum.

\section{Conclusions}

The research includes testing of various grades of stone mastic asphalt and dense graded asphalt with different types of aggregate and binder, test and materials were made according to Russian (GOST) series of standards. Russian series of standards include dense-graded and stone mastic hot mix asphalt with nominal maximum sizes 5/10/15/20 $\mathrm{mm}$ regulation. Experiments were performed using the Prall Test system which precisely allows predicting and evaluating of the abrasion resistance of the pavement materials.

Series of the experiment shows that abrasion resistance depends on the different properties of the pavement materials. The use of coarse aggregate and the use of SMA mixes instead of dense-graded mixes reduce the wear of asphalt concrete. Experiments show, that quality of binder also reduces it, thus using the styrene-butadiene-styrene polymer modified bitumen improves the abrasion resistance more than 10-20 percent. Abrasion resistance of the aggregate also has a big impact on quality of the asphalt concrete.

Besides, the experiments show that air voids content can aggravate the abrasion resistance of the pavement materials. This effect depends on the several processes as an aggregate particles loosing and cracking. This conclusion also imposes restrictions on the compaction process, which excludes the destruction and cracking of the aggregate particles.

This study plays an important role in the development of road construction organizations of the Republic of Tatarstan and includes practical recommendations for improving the wear resistance of pavements. Expansion of these experimental results will make it possible to build correlation dependences necessary for high-quality and accurate designing of asphalt concrete with a given value of wear resistance for use in certain conditions. 


\section{References}

1. D. B. Makarov, N. M. Krasinikova, N. M. Morozov, D. A. Ayupov, I. V. Borovskikh, O. V. Khokhryakov, E. M. Yagund, V. G. Khozin, Improving the Quality of Materials for Highway Construction, Journal of Engineering and Applied Sciences, 11, 14, 30353041 (2017)

2. V. Ushakov, D. Jelagin, G. Dyakov, S. Dmitriev, M. Goryachev, Field evaluation of rutting in concrete pavements, IOP Conf. Ser.: Mater. Sci. Eng., 832, 012033 (2020) DOI: $10.1088 / 1757-899 \mathrm{X} / 832 / 1 / 012033$

3. A. Bahadori, K. Zhang, X. Li, X. Muhunthan, Development of asphalt materials to mitigate sdudded tire wear of pavements, Washington State University, California State University, Chico, California State University, Fresno, Final Report (2017) DOI: 10.13140/RG.2.2.23938.02243

4. T. Jacobson, Study of the wear resistance of bituminous mixes to studded tyres - Test with slabs of bituminous mixes inserted in roads and the VTI's road simulator, Lecture at the Meeting of Nordic Road Association NVF Committee 33, Tällberg, Sweden (1994)

5. U. Olofsson, M. Tu, O. Noskoa, Y. Lyua, S. Dizdara, A pin-on-disc study of airborne wear particle emissions from studded tyre on concrete road contacts, Wear, 410-411, 165-172 (2018) DOI: 10.1016/j.wear.2018.06.012

6. B. Snilsberg, R. G. Saba, N. Uthus, Asphalt pavement wear by studded tires - Effects of aggregate grading and amount of coarse aggregate, in proccedings of the 6th Eurasphalt\&Eurobitume Congress. Prague, Czech Republic. (2016) DOI:dx.doi.org/10.14311/EE.2016.072

7. B. Kekec, N. Bilim, S. Dindar, Abrasion properties of some building stone wastes and usability for sustainability, Geo-Resources Environment and Engineering, 218-222 (2017) DOI: 10.15273/gree.2017.02.039

8. K. Ravindra, D. Gurmel, S.Ghataora, J. Lynn, Road Pavements, Sustainable Construction Materials Sewage Sludge Ash, 209-223 (2017) DOI: 10.1016/B978-0-08-100987$1.00008-1$

9. G. Licitra, L. Teti, M. Cerchiai, F. Bianco, The influence on the use of the CPX method for evaluating the effectiveness of a noise mitigation action based on low-noise road surfaces, Transport. Res. Part D Transp. Environ., 55, 217-226 (2017) DOI: 10.1016/j.trd.2017.07.002

10. A. V. Korochkin, Influence of Type and Thickness of Cement-Concrete on the Calculation of Rigid Road Surfaces with Asphalt-Concrete Pavement, IOP Conference Series Materials Science and Engineering, 753, 022029 (2020) DOI: 10.1088/1757899X/753/2/022029

11. D. Siebert, H. Mork, Prall tests to study the effect of mortar on the wear of Norwegian asphalt mixtures. In proccedings of the 6th Eurasphalt \& Eurobitume Congress, Prague, Czech Republic, 1-3 (2016) URL: www.h-a-d.hr/pubfile.php?id=929 (last accessed: 25.03.2021)

12. S. Badeli, A. Carter, G. Doré, The Importance of Asphalt Mixture Air Voids on the Damage Evolution During Freeze-Thaw Cycles, in Proceedings of the Sixth-First Annual Conference of the Canadian Technical Asphalt Association (CTAA), Banff, Alberta (2016)

13. Gun Y Lee, C. K. H. Dharan, R. O. Ritchie, A physically-based abrasive wear model for composite materials, Wear, 252, 322-331 (2002) DOI: 10.1016/S00431648(01)00896-1 
14. A. Hassan, M. Mahmud, N. Adi, N. Rahmat, M. Hainin and R. P. Jaya, Effects of Air Voids Content on The Performance of Porous Asphalt Mixture, Journal of Engineering and Applied Sciences, 11, 20, 11884-11887 (2016)

15. A. M. Zaltuom, A Review Study of The Effect of Air Voids on Asphalt Pavement Life. In proccedings of the First Conference for Engineering Sciences and Technology (2018) DOI: $10.21467 /$ proceedings.4.29

16. J. Hu, P. Liu, B. Steinauer, A study on fatigue damage of asphalt mixture under different compaction using 3D-microstructural characteristics, Front. Struct. Civ. Eng., 11, 329-337 (2017) DOI: 10.1007/s11709-017-0407-9

17. Abdul-Rahim Ibrahim Al-Hadidy, Effect of Styrene-Butadiene-Styrene on Asphalt and Stone Matrix Asphalt Mixture Properties, Journal of Materials in Civil Engineering 23(1) (2018) DOI: 10.1061/(ASCE)MT.1943-5533.0000185

18. B. B. Teltayev, Importance of rocks in road construction, News of the National Academy of Sciences of the Republic of Kazakhstan, Series of Geology and Technical Sciences, 423(3), 283-292 (2017)

19. A. Kolos, A. Konon, P. Chistyakov, Change of ballast strength properties during particle abrasive wear, Procedia Engineering, 189, 908-915 (2017) DOI: 10.1016/j.proeng.2017.05.141

20. C. C. Celma, D. Jelagin, M. Partl, P. L. Larsson, Contact-induced deformation and damage of rocks used in pavement materials, J. of Mater. and Design, 133(5) (2017) DOI: 10.1016/j.matdes.2017.08.003

21. İ. Gökalp, V. E. Uz, M. Saltan, Testing the abrasion resistance of aggregates including by-products by using Micro Deval apparatus with different standard test methods, Construction and Building Materials, 123, 1-7 (2016) DOI: 10.1016/j.conbuildmat.2016.06.141

22. I. Gökalp, E. U. Volkan, The effect of aggregate type and gradation on fragmentation resistance performance: Testing and evaluation based on different standard test methods, Transportation Geotechnics, $22 \quad$ (2020) DOI: https://doi.org/10.1016/j.trgeo.2019.100300

23. V. F. Vázquez, F. Terán, J. Luong, S. Paje, Functional Performance of Stone Mastic Asphalt Pavements in Spain: Acoustic, Assessment in Coatings, 9(2), 123 (2019) DOI: 10.3390/coatings 9020123 